OPEN ACCESS

Edited by:

Jienan Pan,

Henan Polytechnic University, China

Reviewed by: Yong Li,

China University of Mining and Technology, China

Zhaobiao Yang,

China University of Mining and

Technology, China

*Correspondence:

Songhang Zhang

zhangsh@cugb.edu.cn

Specialty section: This article was submitted to

Economic Geology,

a section of the journal

Frontiers in Earth Science

Received: 14 January 2022 Accepted: 07 February 2022

Published: 28 February 2022

Citation:

Wang $K$, Tang S, Zhang S, Guo Y, Lin D and Niu Z (2022) Numerical

Simulation of Fracture Propagation

Characteristics of Hydraulic Fracturing

in Multiple Coal Seams, Eastern

Yunnan, China.

Front. Earth Sci. 10:854638.

doi: 10.3389/feart.2022.854638

\section{Numerical Simulation of Fracture Propagation Characteristics of Hydraulic Fracturing in Multiple Coal Seams, Eastern Yunnan, China}

\author{
Kaifeng Wang ${ }^{1,2,3}$, Shuheng Tang ${ }^{1,2,3}$, Songhang Zhang ${ }^{1,2,3 *}$, Yingying Guo ${ }^{1,2,3}$, \\ Donglin Lin ${ }^{1,2,3}$ and Zhichao Niu ${ }^{1,2,3}$
}

${ }^{1}$ School of Energy Resources, China University of Geosciences (Beijing), Beijing, China, ${ }^{2}$ Coal Reservoir Laboratory of National Engineering Research Center of CBM Development \& Utilization, Beijing, China, ${ }^{3}$ Beijing Key Laboratory of Unconventional Natural Gas Geological Evaluation and Development Engineering, Beijing, China

As a reservoir reconstruction technology, hydraulic fracturing is a key method to improve the production of coalbed methane (CBM) wells. The CBM reservoir in eastern Yunnan, an important CBM exploration and development zone in China, is characterized by multiple thin coal seams. Compared to the fracturing of the single-layer coal seam, the combined seam fracturing technology is more difficult and complex. To study the fracture propagation characteristics and influencing factors of hydraulic fracturing in multiple coal seams, taking No. 9 and No. 13 coal seams as the research objects, the fracturing process was numerically simulated by using the finite element method and ANSYS software in this work. Based on the mathematical model of low permeable coalrock mass, a two-dimensional hydraulic fracture model was established. In addition, the fracture geometries of combined seam fracturing were studied quantitatively. The results indicate that although No. 9 coal and No. 13 coal seams have similar rock mechanical properties, the propagation process and final geometry of a fracture are different. The reliability of the simulation results is verified by the comparison of experimental parameters and field investigation. The results prove the feasibility of combined seam fracturing in eastern Yunnan. The high Young's modulus and thickness of the coal seam make the fracture geometry longer, but the fracture height is smaller. The low Young's modulus, high Poisson's ratio, and thickness of the No. 13 coal seam result in an increase in the length and height of the No. 9 coal seam. The increase in Young's modulus of interlayer inhibits the propagation of fractures, while the high thickness and low Poisson's ratio of interlayers facilitate the extension of the length and inhibit the extension of the height. This work provides a case reference for combined seam fracturing of coal reservoirs and has practical significance for the development of CBM characterized by multiple coal seams in eastern Yunnan.

Keywords: eastern Yunnan, multiple coal seams, combined seam fracturing, coalbed methane, numerical simulation 


\section{INTRODUCTION}

The coal matrix permeability is low in China; thus, reservoir reconstruction is generally conducted to improve the performance of producing wells and increase recovery (Islam et al., 2009; Meng et al., 2011; Lekontsev and Sazhin, 2015; Li et al., 2020; Zhang et al., 2020). Hydraulic fracturing of CBM wells has been widely practiced as an effective method to increase the drainage efficiency of low-permeability, low-pressure, and lowsaturated coal seams. McDaniel et al. (1990) were the first people to apply hydraulic fracturing to the stimulation work of CBM wells. The initiation and propagation of hydraulic fractures in coal seams are complicated, which limits efficient implementation of hydraulic fracturing (Wessling et al., 2008; Yang et al., 2015; Jun Lu et al., 2020). Scholars have conducted a lot of research on theories and techniques of hydraulic fracturing treatment. Warpinski and Teufel et al. (1987) revealed from field results that the in-situ stress and fluid pressure could influence the hydraulic fracturing procedure. The effects of elastic modulus, Poisson's ratio, and in-situ stress on fracture geometry were studied by means of experiment and field investigation (Liang et al., 2017; Chen et al., 2019; Hu et al., 2020; Liu et al., 2020). For instance, Li et al. (2014) comprehensively studied the effect of the formation mechanical property (in-situ stress, elastic modulus, and permeability) differences between adjacent layers over hydraulic fracture propagation, and it turned out that the mechanical properties of strata have a great influence on the fracture extension; Yinlong $\mathrm{Lu}$ et al. (2020) investigated the influence of the intermediate principal stress on the mechanical properties of cubic coal and soft sandstone under two different true triaxial loading conditions and discussed the influence interval of the intermediate principal stress on the strength of sandstone and coal in detail. In addition, an experimental study was conducted to study liquid nitrogen-induced rock/coal failures under true triaxial stress conditions in order to investigate fracture propagation behaviors under in-situ geological conditions with liquid nitrogen injections. Many scholars have investigated the seismic response of naturally fractured coal to stress and hydraulic fracturing, with an emphasis on identifying the temporal and spatial behaviors of fractures using the active acoustic-monitoring technique (Qin et al., 2018; Zhang et al., 2018; Jiang et al., 2020; Cao et al., 2021; Li et al., 2021).

In recent years, scholars have done a lot of numerical simulation research on hydraulic fracture propagation of CBM reservoirs and made remarkable progress. Zhang et al. (2014) presented a twophase, 3D flow, and hydraulic fracturing model of dual-porosity media based on the theories of oil-gas geology and mechanics of flow through porous media. Correspondingly, a finite difference numerical model has been developed and applied successfully to a CBM reservoir. Li and Xing et al. (2015) demonstrated that under a constant hydraulic pressure boundary, with higher values of permeability, porosity, Young's modulus, and Poisson's ratio, hydraulic fracturing initiates earlier. Jiang et al. (2016) developed a hydraulic fracture numerical simulation model to quantitatively study the effects of different geological and operational factors on the fracture propagation in CBM reservoirs. Based on the rock seepagestress coupling effect, a three-dimensional hydraulic fracture model of multilayer-commingled fracturing in coal strata was established in combination with ABAQUS finite element software. The influence of geological factors and construction factors on the hydraulic fracture propagation in sandstone-coal interbedded reservoirs was investigated (Zhao et al., 2018). Moreover, laboratory experiments and numerical simulation methods were used to investigate the hydraulic fracture propagation law of coal in CBM reservoir with natural fractures. Through the combination of triaxial compression test and numerical simulation of coal and sandstone, the effects of different confining pressure and cleat direction on rock brittleness and fracture characteristics were analyzed (Zhang and Bian, 2015; Xie et al., 2019; Eremin, 2020; Ren et al., 2021; Zhao et al., 2021). However, investigation on the propagation of commingled crack in coal seams which are soft-hard interlaced strata is less studied and not well understood.

Generally, these relevant theories and techniques are mostly applied to the single coal seam or the thick coal seam fracturing treatment. In the eastern Yunnan province, an emerging area for coal measure gas recovery in China, the Permian formation is composed of typical superposed reservoirs with multiple thin coal seam zones (Li et al., 2015; Tang et al., 2016; Yang et al., 2018; Wang and Qin, 2019; Zhang et al., 2021). The characteristic of thin coals eam cannot provide resources guarantee for the development of CBM and increase fracturing costs. Several theoretical and experimental studies have been carried out in the past to investigate multiple reservoirs fracturing treatment and bring us a little inspiration. Nasedkina and Trufanov (2006) established a mathematical model of the process of hydrodynamic fracturing in a multi-layer coal seam based on the equation of continuity and Darcy's law. Jia et al. (2016) suggested some effective stimulation techniques adapting to the superposed reservoirs of coal measures and further studied the mechanism on adaptable hydraulic fracturing of the superposed reservoirs associated with multiple thin coal seams. Ni et al. (2010) researched the key technology of combined seam fracturing and confirmed the practicality of the craft, reducing development costs and overcoming the limitations of geological conditions. The technology has been applied with some success. Multilayer-commingled fracturing is the vital step to achieve gas co-exploration in coal measures. However, the conditions the combined seam fracturing can be implemented was neither clear nor was the effect of the properties of the coal seam and the roof and floor on the propagation of hydraulic fractures.

In this work, a two-dimensional hydraulic fracture model of combined seam fracturing is established in combination with a cohesive element model based on previous studies, and the reliability of the model was verified. ANSYS software was used to quantitatively study combined seam fracturing fracture geometries in the coal seam of eastern Yunnan, China. In addition, influencing factors such as fracturing pressure, Young's modulus, Poisson's ratio, and thickness, which affect the characteristics of fracturing propagation were also investigated.

\section{GEOLOGICAL SETTING}

The study area is in the eastern Yunnan region, which is an important coal- and CBM-rich area in southwest China (Figure 1A). The period 


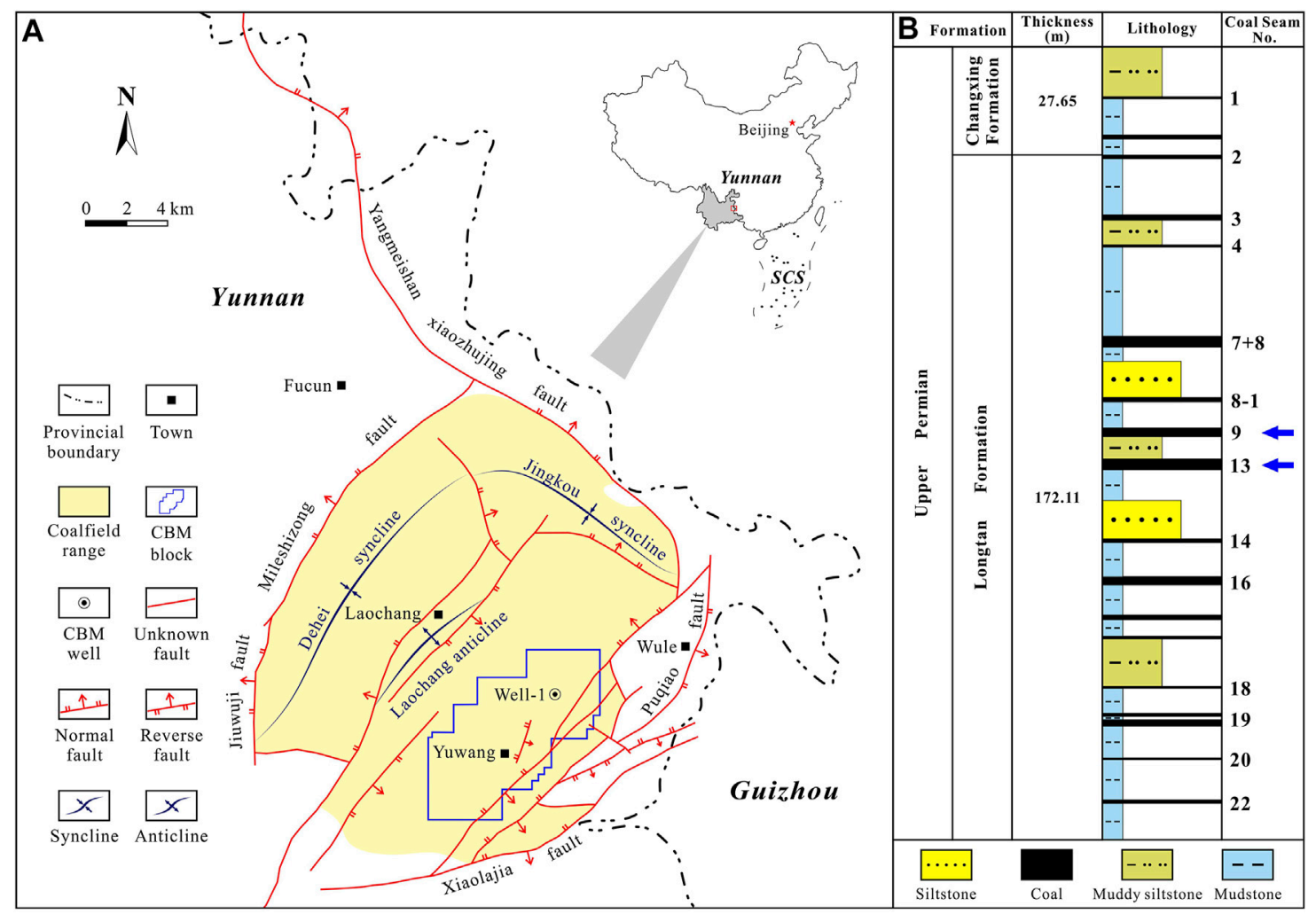

FIGURE 1 | (A) Map showing location and structure outline of the study area in the eastern Yunnan province. (B) The lithology column of the coal measure strata of Well-1 in the study area.

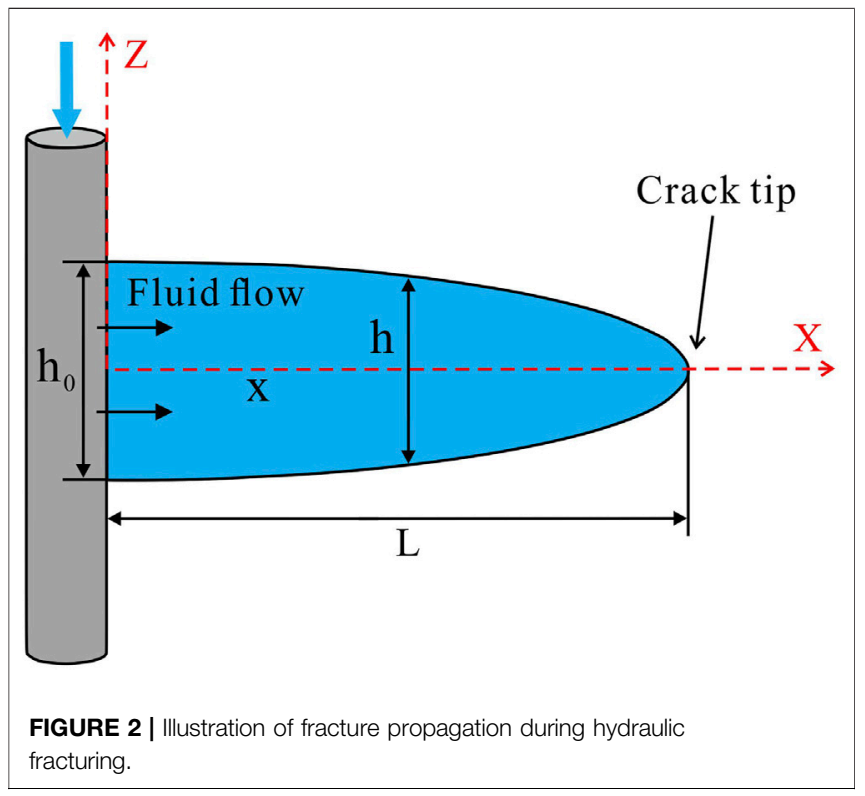

of the coal-bearing rock formation was in the late Permian. The coal measure strata have since experienced varying natures, directions, and intensities of different Yanshanian and Himalayan tectonic activities, causing strong deformation to the coal measure strata

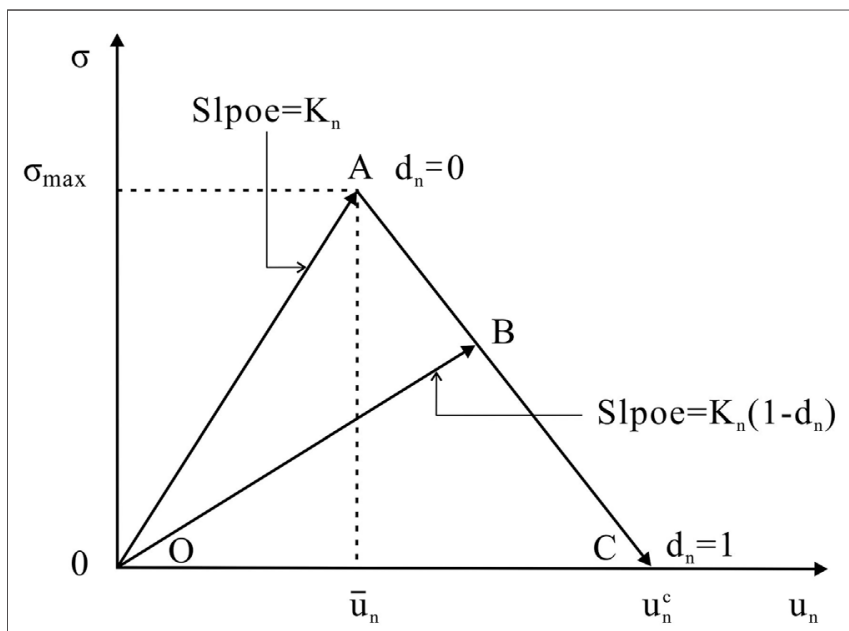

FIGURE 3 | Normal contact stress and the contact gap curve for the cohesive zone material.

and extensive fault development, resulting in a complicated geological background. Faults are compressional, reach shear fracture pressure, and are steeply dipping, generally at an angle of 60-85 (Guoxi et al., 2020; Lan et al., 2020). The CBM block is located in the southeast wing of the Laochang anticline. It is a relatively gentle 


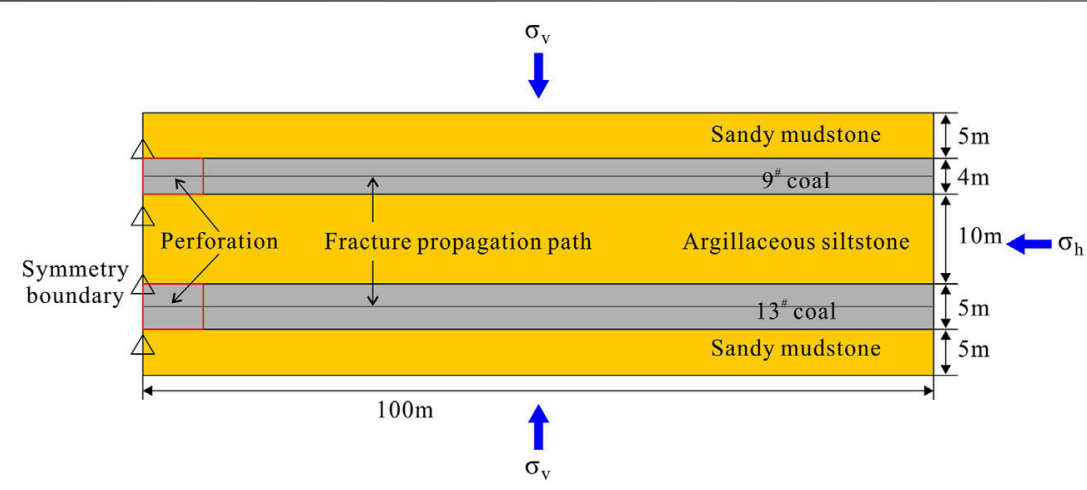

FIGURE 4 | Two-dimensional hydraulic fracturing model.

TABLE 1 | Basic parameters of the model.

\begin{tabular}{|c|c|c|c|c|c|}
\hline Items & Unit & $\begin{array}{c}\text { No. } 9 \\
\text { coal seam }\end{array}$ & $\begin{array}{c}\text { No. } 13 \\
\text { coal seam }\end{array}$ & $\begin{array}{l}\text { Argillaceous } \\
\text { siltstone }\end{array}$ & Sandy mudstone \\
\hline Elasticity modulus & $\mathrm{GPa}$ & 2.250 & 4.420 & 9.650 & 16.135 \\
\hline Poisson's ratio & - & 0.237 & 0.231 & 0.240 & 0.315 \\
\hline Tensile strength & $\mathrm{MPa}$ & 1.1 & 1.2 & - & - \\
\hline Injection rate & $\mathrm{m}^{3} / \mathrm{min}$ & 7 & 7 & - & - \\
\hline Fracturing fluid viscosity & $\mathrm{mPa} \cdot \mathrm{s}$ & 5 & 5 & - & - \\
\hline
\end{tabular}

monoclinal structure. The stratum strikes NE, tends to SE, and there are few faults in the study area.

The coal measure strata in the study area are the upper Permian Changxing and Longtan Formations, which are mainly composed of dark gray fine clastic rock, siltstone, sandy mudstone, and coal. The burial depth of the coal seams in the study area varies greatly. They are generally buried to a depth of 500-1,500 $\mathrm{m}$ and are generally less than $1,000 \mathrm{~m}$. The coal seams are mainly distributed in the middle and upper part of the Longtan Formation and are mainly thin, medium, and thick coal, including 27-42 coal seams, with a total thickness of $41 \mathrm{~m}$. The thickness of a single layer of coal is generally less than $5 \mathrm{~m}$, with the characteristics of many thin coal seams (Ju et al., 2018; Yang et al., 2019; Chen et al., 2021). The gas content of the coal seam is $9.23-26.20 \mathrm{~m}^{3} / \mathrm{t}$, with an average of $15.20 \mathrm{~m}^{3} / \mathrm{t}$, and increases gradually with the increase of depth. The CBM reservoirs belong to a micro under-pressure reservoir. The main coal seams in the study area are No. $7+8$, No. 9, No. 13, and No. 19 in the Longtan Formation (Figure 1B). In this paper, No. 9 and No. 13 coal reservoirs are taken as the research objects to carry out the numerical simulation analysis of combined seam fracturing.

\section{MATHEMATICAL MODEL OF COAL-ROCK MASS}

\subsection{Hydraulic Pressure Model to Analyze the Fracturing Phenomena}

The longitudinal mathematical model of the reservoir was established based on the KGD model (Geertsma and Clerk,
1969; Chen, 2012). We have assumed that the shape of the fracture is elliptical with a vertical profile and the width of the fracture is constant as shown in Figure 2. This model is based on several assumptions. The coal-rock material is an isotropic linear elastic material, the coal seam belongs to the same pressure system, and the middle rock stratum is an impermeable layer. The filtration loss of fracturing fluid along the fracture is zero. In the process of hydraulic fracturing, the liquid column pressure difference between the upper and lower fracturing layers is ignored. Moreover, the fluid filtration of the fracturing and the seepage and coupling effects of the fluid and coal matrices in the coal seam were not considered. For a Newtonian fluid, in order to simplify, we neglected the gravitational forces and assumed that the flow in the fracture is tangential. The tangential flow within the gap is governed by the lubrication equations (Batchelor, 1967) formulated from Poiseuille's law. The hydraulic pressure equation in the fracture can be written as:

$$
\begin{aligned}
\frac{\partial p}{\partial x} & =-\frac{12 q v}{\boldsymbol{w h}^{3}}\left(\boldsymbol{p} \geq \boldsymbol{p}_{\boldsymbol{c}}\right), \\
\boldsymbol{h} & =\boldsymbol{h}_{0} \sqrt{1-\boldsymbol{x}^{2} / \boldsymbol{L}^{2}},
\end{aligned}
$$

and since it is generally considered that the fluid pressure on the fracture surface near the crack tip is not less than the closure pressure, we have

$$
p=p_{c}\left(p<p_{c}\right)
$$

where $\mathrm{p}$ is the hydraulic pressure, $v$ is the fracturing fluid viscosity, $\mathrm{q}$ is the flow rate of a single wing, $\mathrm{w}$ is the fracture 
A

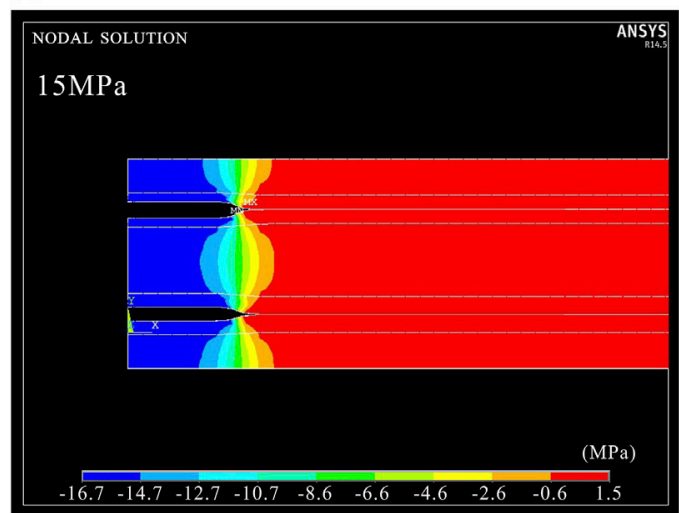

C

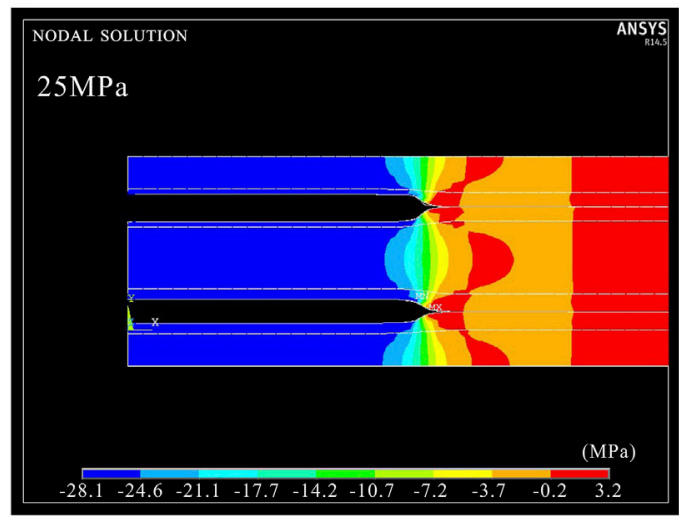

B

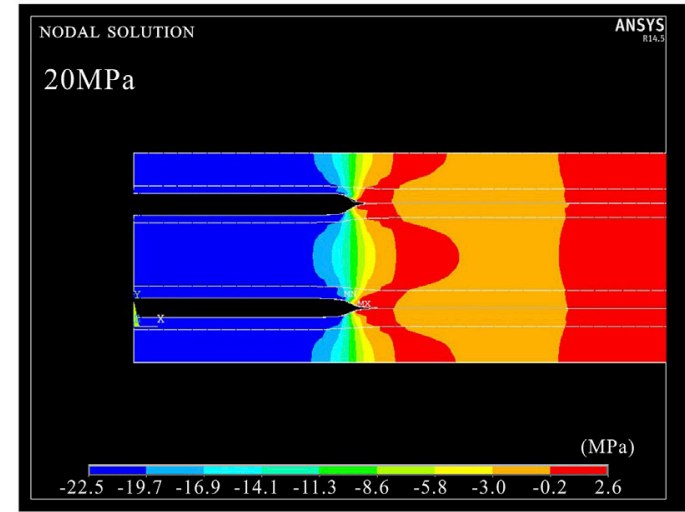

D

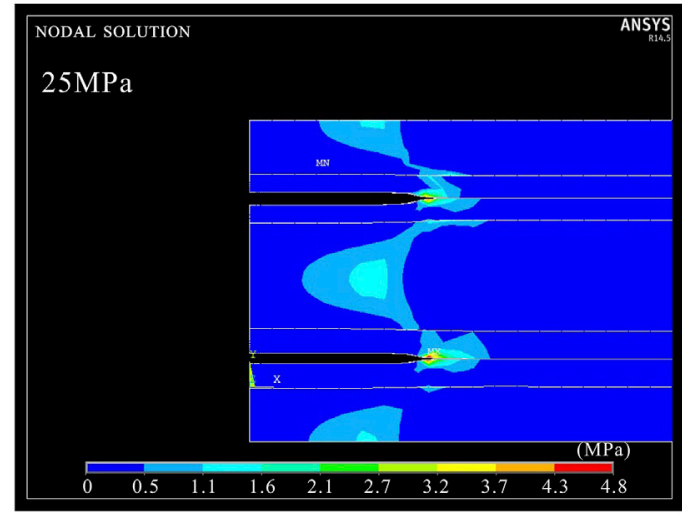

FIGURE 5 | The combined seam fracturing simulation result and the stress contour plot. (A) The stress contour plot along the $Y$-axis under a pressure of $15 \mathrm{MPa}$.

(B) The stress contour plot along the $Y$-axis direction under a pressure of $20 \mathrm{MPa}$. (C) The stress contour plot along $Y$-axis under a pressure of $25 \mathrm{MPa}$. (D) The first principal stress contour plot under a pressure of $25 \mathrm{MPa}$.

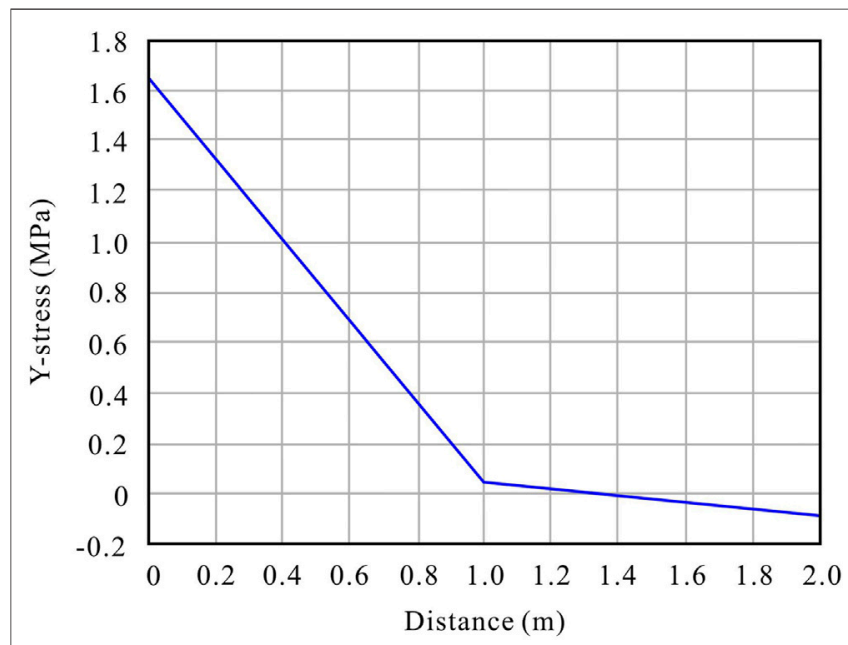

FIGURE 6 | Y-direction tensile stress at the leading edge of the crack tip.

width, $\mathrm{L}$ is the fracture length, $\mathrm{h}$ is the fracture height, $\mathrm{h}_{0}$ is the maximum height, $\mathrm{p}_{\mathrm{c}}$ is the closure pressure, and $\mathrm{x}$ is the distance from any point to the wellbore on the fracture surface.

\subsection{Initiation and Propagation Criteria for the Cohesive Element}

The cohesive zone model (CZM) is used to describe the separation of interfaces and fracture propagation. The separation mode of the interface is the normal separation. The cohesive zone material is shown in Figure 3, $\sigma$ is the normal contact stress (tension), and $u_{n}$ is the contact gap (Shet and Chandra, 2002; Tomar et al., 2004). When the stress reaches the maximum normal contact stress $\sigma_{\max }$, element damage occurs, and the stiffness gradually degrades until it is reduced to 0 (point $\mathrm{A}$ ). Debonding is completed at point $\mathrm{C}$ when the normal contact stress $\sigma$ reaches 0 , and further separation occurs without any normal contact stress. After debonding has been initiated, it is assumed to be cumulative and any unloading and subsequent reloading occur in a linear elastic manner along the line $\mathrm{OB}$ at a more gradual slope. The equation for the curve OAC can be written as:

$$
P=K_{n} u_{n}\left(1-d_{n}\right) .
$$

The debonding parameter is defined as:

$$
d_{n}=\left(\frac{\boldsymbol{u}_{n}-\overline{\boldsymbol{u}}_{n}}{\boldsymbol{u}_{n}}\right)\left(\frac{\boldsymbol{u}_{n}^{c}}{\boldsymbol{u}_{n}^{c}-\overline{\boldsymbol{u}}_{n}}\right)
$$



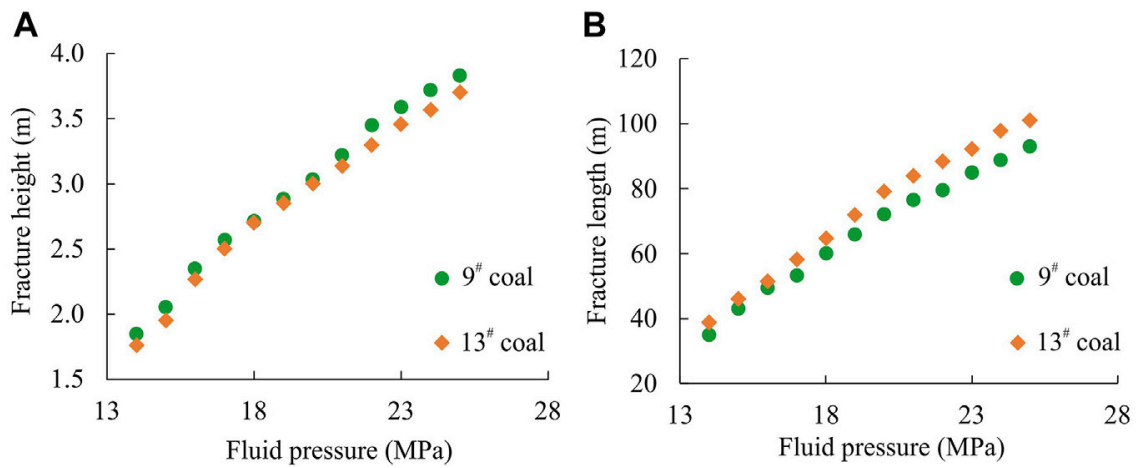

FIGURE 7 | Relationship of fracturing pressure and fracture propagation. (A) Fracture height and (B) fracture length.
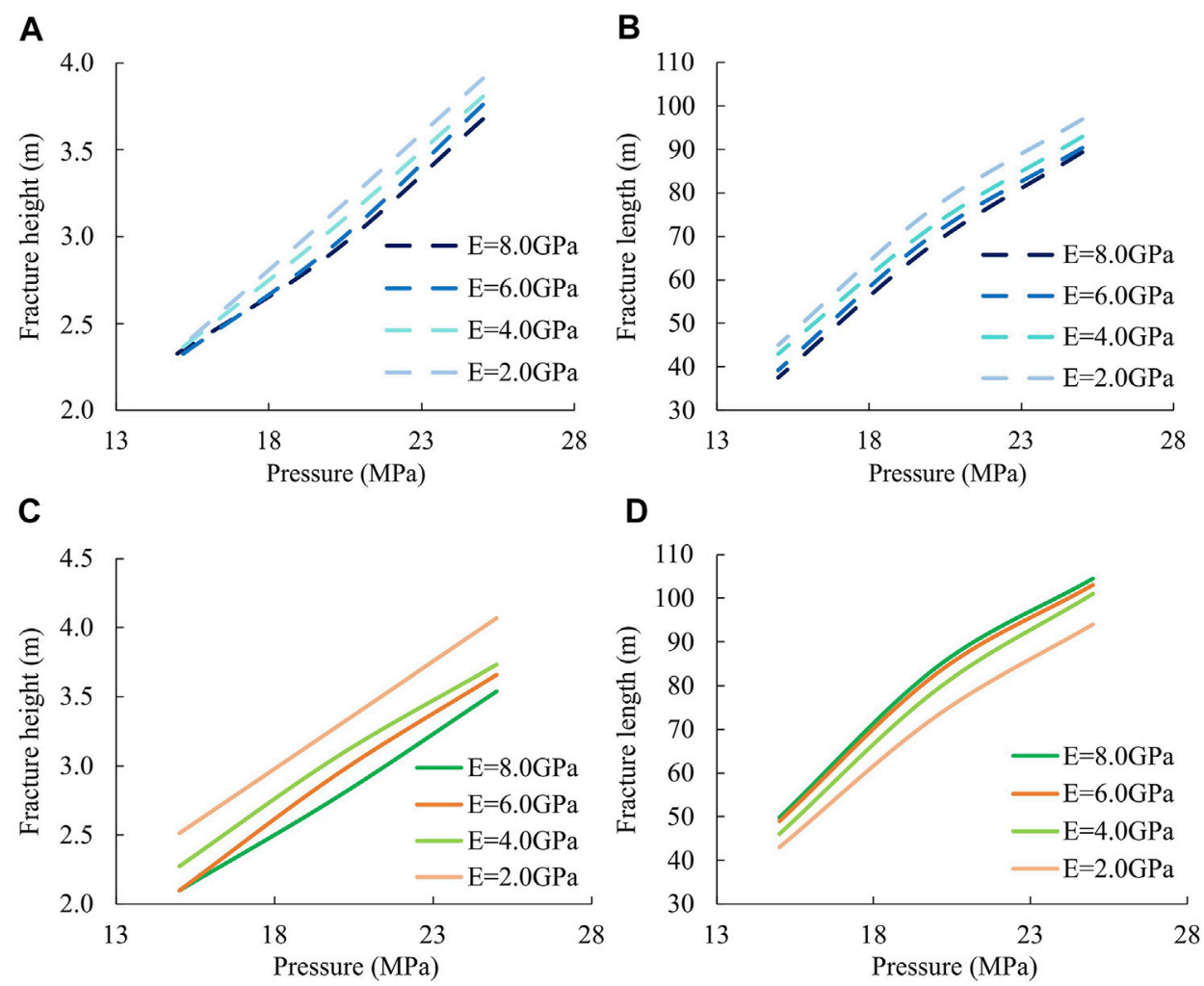

FIGURE 8|Fracture parameters under different Young's modulus of the No. 13 coal seam. (A) The fracture height of the No. 9 coal seam. (B) The fracture length of the No. 9 coal seam. (C) The fracture height of the No. 13 coal seam. (D) The fracture length of the No. 13 coal seam.

with

$$
\begin{gathered}
\left\{\begin{array}{c}
\boldsymbol{d}_{\boldsymbol{n}}=0, \Delta \boldsymbol{n} \leq 1 \\
0<\boldsymbol{d}_{\boldsymbol{n}} \leq 1, \Delta \boldsymbol{n}>1
\end{array},\right. \\
\Delta \boldsymbol{n}=\frac{\boldsymbol{u}_{\boldsymbol{n}}}{\overline{\boldsymbol{u}}_{\boldsymbol{n}}},
\end{gathered}
$$

where $P$ is the normal contact stress (tension), $K_{n}$ is the normal contact stiffness, $u_{n}$ is the contact gap, $\bar{u}_{n}$ is the contact gap at the maximum normal contact stress (tension), $u_{n}^{c}$ is the contact gap at the completion of debonding, and $d_{n}$ is the debonding parameter.

\section{NUMERICAL SIMULATION MODEL AND PARAMETERS}

The CBM reservoir simulated is in eastern Yunnan, China, with multiple thin coal seams. The objects of combined seam 

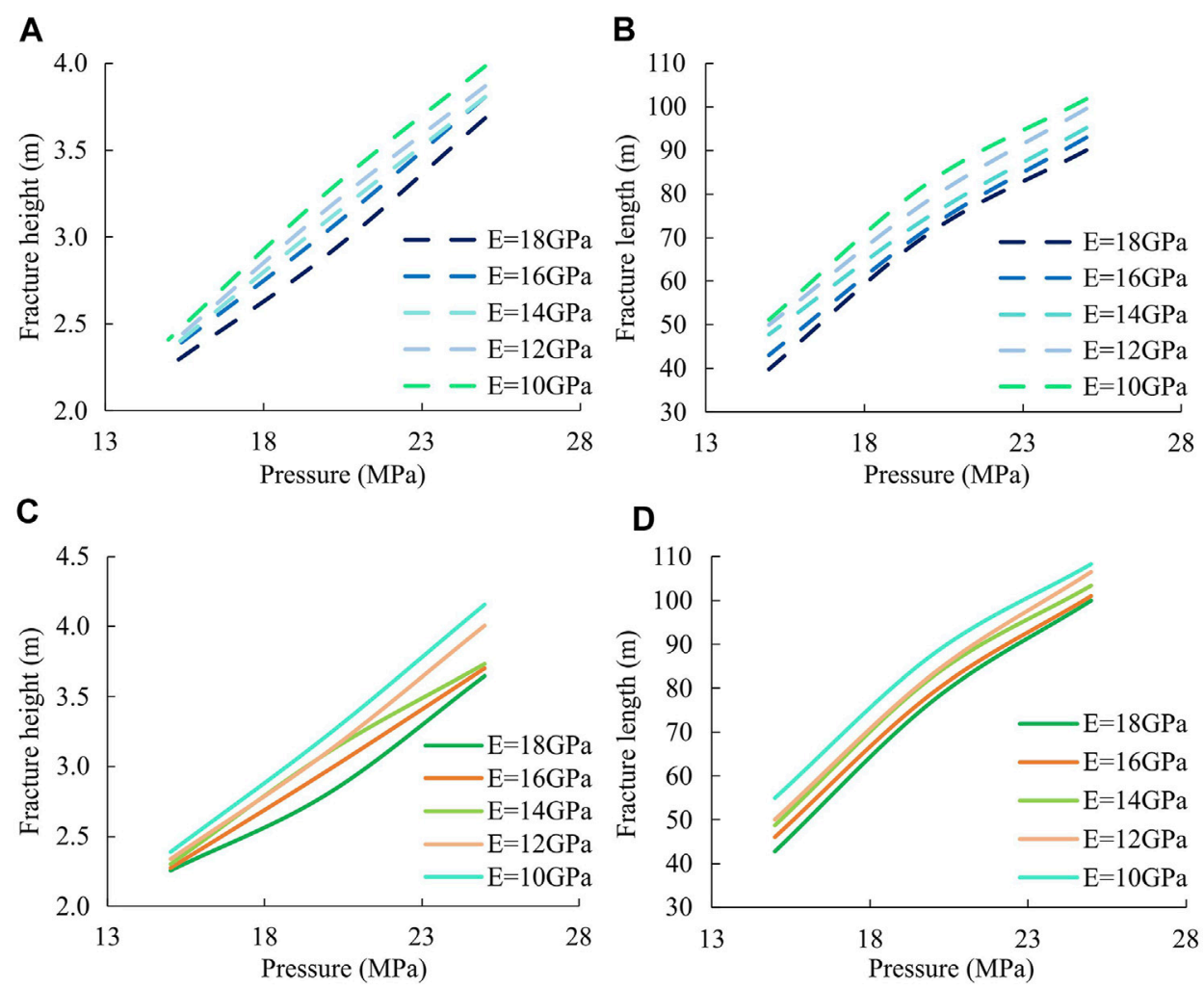

FIGURE 9|Fracture parameters under different Young's modulus of the roof and floor. (A) The fracture height of the No. 9 coal seam. (B) The fracture length of the No. 9 coal seam. (C) The fracture height of the No. 13 coal seam. (D) The fracture length of the No. 13 coal seam.

fracturing are the No. 9 and No. 13 coal seams that belong to the upper Permian Longtan formation of Well-1 (Figure 1B). The seams are favorable reservoirs because early exploration and the production test of the well showed potential for coalbed methane exploitation. Moreover, taking No. 9 and No. 13 coal seams as target reservoirs, the combined seam-fracturing project of Well-1 has been completed, which provides the verification conditions for this numerical simulation research. In addition, the two coal seams represent multiple coal seams, which also improves the effectiveness of numerical simulation results.

\subsection{Numerical Model of Hydraulic Fracturing}

The two-dimensional model is shown in Figure 4. Due to the symmetry of the problem, only one-half of the original model is studied. It is a rectangle with a length of $100 \mathrm{~m}$ and a height of $24 \mathrm{~m}$. The directions of the $X$ and $Y$ axes represent the principal horizontal stress and vertical stress. The vertical depth of the No. 9 coal seam roof is $-682.3 \mathrm{~m}$, and the thickness is $4 \mathrm{~m}$, and the depth of the No. 13 coal seam roof is $-696.3 \mathrm{~m}$ and the thickness is $5 \mathrm{~m}$. The roof and the floor are basically parallel to the coal seam with the top depths of $-677.3 \mathrm{~m}$ and $-701.3 \mathrm{~m}$, respectively. Their thicknesses are approximately $5 \mathrm{~m}$, and the thickness of the interlayer is $10 \mathrm{~m}$. The fracture propagation path is located in the center of the coal seam. The length of the perforation is $1 \mathrm{~m}$. The top and bottom of the model adopt the boundary conditions of the $Y$ direction displacement, which means the relative displacements of vertical directions are zero. The right of the model adopts the boundary conditions of the $X$ direction displacement to limit the horizontal displacement or deformation. The equivalent overburden pressure acts on the top of the model, considering the typical unit weight of the overlaying rock mass. Also, its value of $19 \mathrm{MPa}$ is calculated according to the actual depth of the overlying formation and the average density of the stratum. The horizontal stress of $23 \mathrm{MPa}$ is applied at the right boundary according to the formula (Zhang and Roegiers, 2010). In this research, the initial stress is set as the same value in order to study the effects of other parameters.

\subsection{Model Parameters}

The basic mechanical parameters were measured from laboratory tests of real coal samples (Table 1). The injection rate and fracturing fluid viscosity are $7 \mathrm{~m}^{3} / \mathrm{min}$ and $5 \mathrm{mPa} \cdot \mathrm{s}$ respectively, which were determined by field operation. The fracturing pressure varies from 10 to $25 \mathrm{MPa}$ in $0.1 \mathrm{MPa}$ increments. The different cases are studied by using material parameters for sensitivity analysis to evaluate their influences on the hydraulic fracture propagation. The typical values of Poisson's ratio of coal range from 0.2 to 0.48 (Gercek, 2007), and in this article, Poisson's ratio has been selected as $0.3,0.4$, and 0.5 , which combined the categorization of Poisson's ratio and lots 

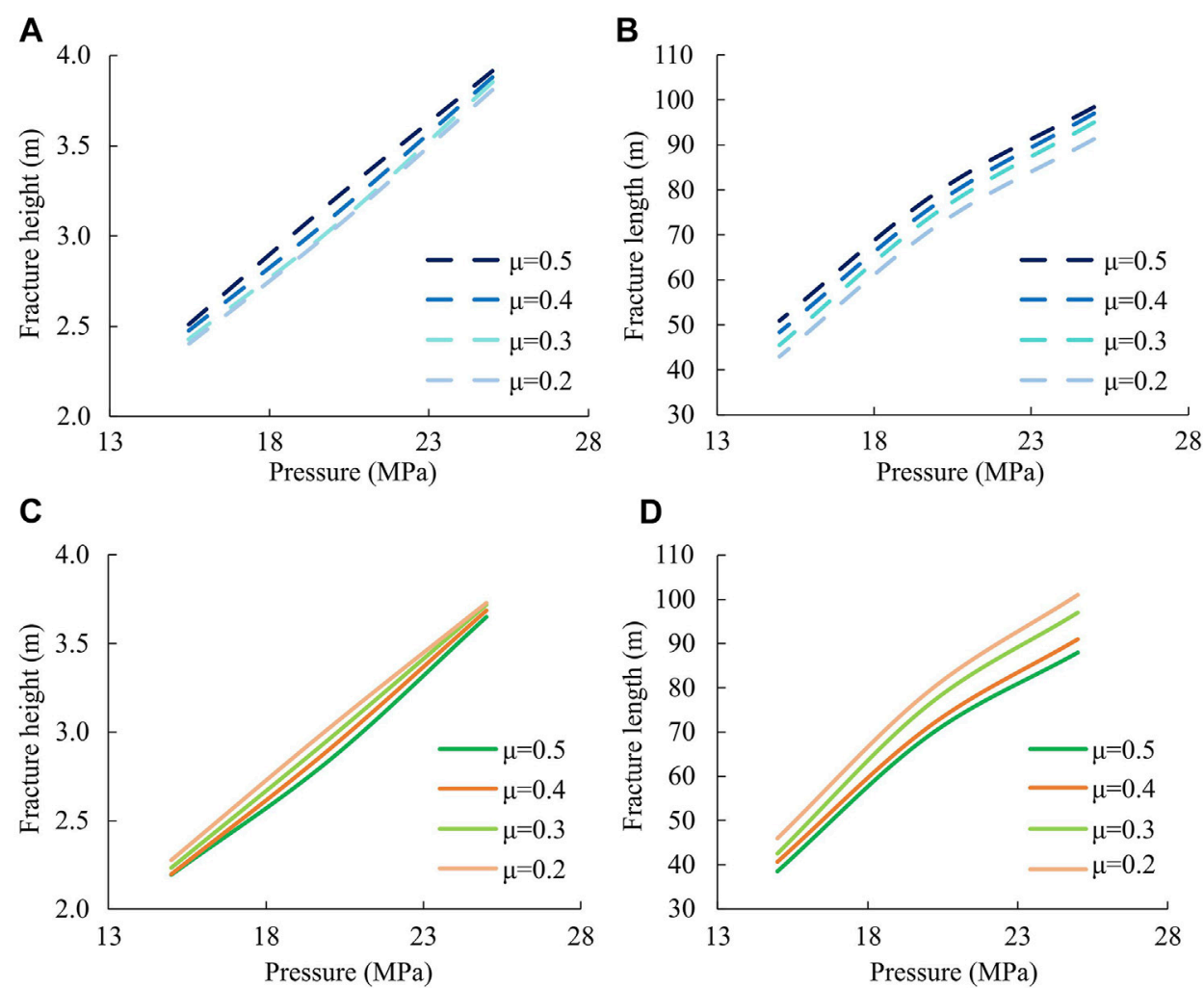

FIGURE 10 | Fracture parameters under different Poisson's ratio of the No. 13 coal seam. (A) The fracture height of the No. 9 coal seam. (B) The fracture length of the No. 9 coal seam. (C) The fracture height of the No. 13 coal seam. (D) The fracture length of the No. 13 coal seam.

of test results, and the Young's modulus have been set at a range of 2-8 GPa (Özgen Karacan, 2009; Pan et al., 2013; Zhang et al., 2017). Similarly, the physical parameters of adjacent layers have been chosen based on the experiment and in-situ tests.

\section{SIMULATION RESULTS AND DISCUSSION}

\subsection{Characteristics of Hydraulic Fractures}

The implementation of the combined seam fracturing depends on whether the fracture can initiate and extend. Fracturing pressure is applied to coal seams, starting from $10 \mathrm{MPa}$. As the pressure increases, the tensile stress generated by the fracturing fluid on the crack surface increases. When the stress is greater than the tensile strength of the coal seam, the coal seam begins to crack and the fracture extends. Figure $\mathbf{5 A - C}$ shows the fracture's morphological characteristics and propagation process of No. 9 coal and No. 13 coal seams under different pressures. The geometry of the fracture is similar to that of an ellipse. The fracture height and length increase with the increase in the fluid pressure. However, the fracture's opening exhibits a certain temporal order as the mechanical properties of different coal seams are different (Zhao et al., 2018), and the fracture initiation of No. 9 coal is earlier than No. 13 coal and the initial pressures are 13.31 and $13.89 \mathrm{MPa}$, respectively. It can be seen from
Figure 5D that stress concentration distinctly occurs in the crack tip during the fracture initiation and extension. From Figure 6, it was found that at the leading edge of the crack tip, the component of the tensile stress gradually decreased as the distance from the tip gradually increased. As the distance increased, tensile stress completely disappeared and the stress returned to its original state and became compressive.

It was concluded that the fracture height of the No. 9 coal seam is higher than No. 13 coal seam, and the length of the fracture was reversed under the same pressure by simulating the fracture propagation of the No. 9 and No. 13 coal seams (Figure 7). When the fracturing pressure was $25 \mathrm{MPa}$, the fracture height was 3.81 and $3.70 \mathrm{~m}$, and the fracture length was 93 and $101 \mathrm{~m}$, respectively. Field investigation and engineering monitoring results of Well-1 showed the fracture height was 4.06 and $3.85 \mathrm{~m}$, the fracture length was 89 and $98 \mathrm{~m}$, the percentage errors of fracture height were 6.2 and $3.9 \%$, and the percentage errors of fracture length were 4.5 and $3.1 \%$. The small error shows that the simulation results are relatively authentic and can be further discussed. The mechanical properties and thickness of coal seams are the main influencing factors of the difference in fracture propagation between No. 9 coal and No. 13 coal seams. The detailed instructions will be explained later. On the whole, the simulation effect is reliable owing to the mechanical properties of coal seams, especially the tensile strength and Young's modulus were similar. The reliability of the 

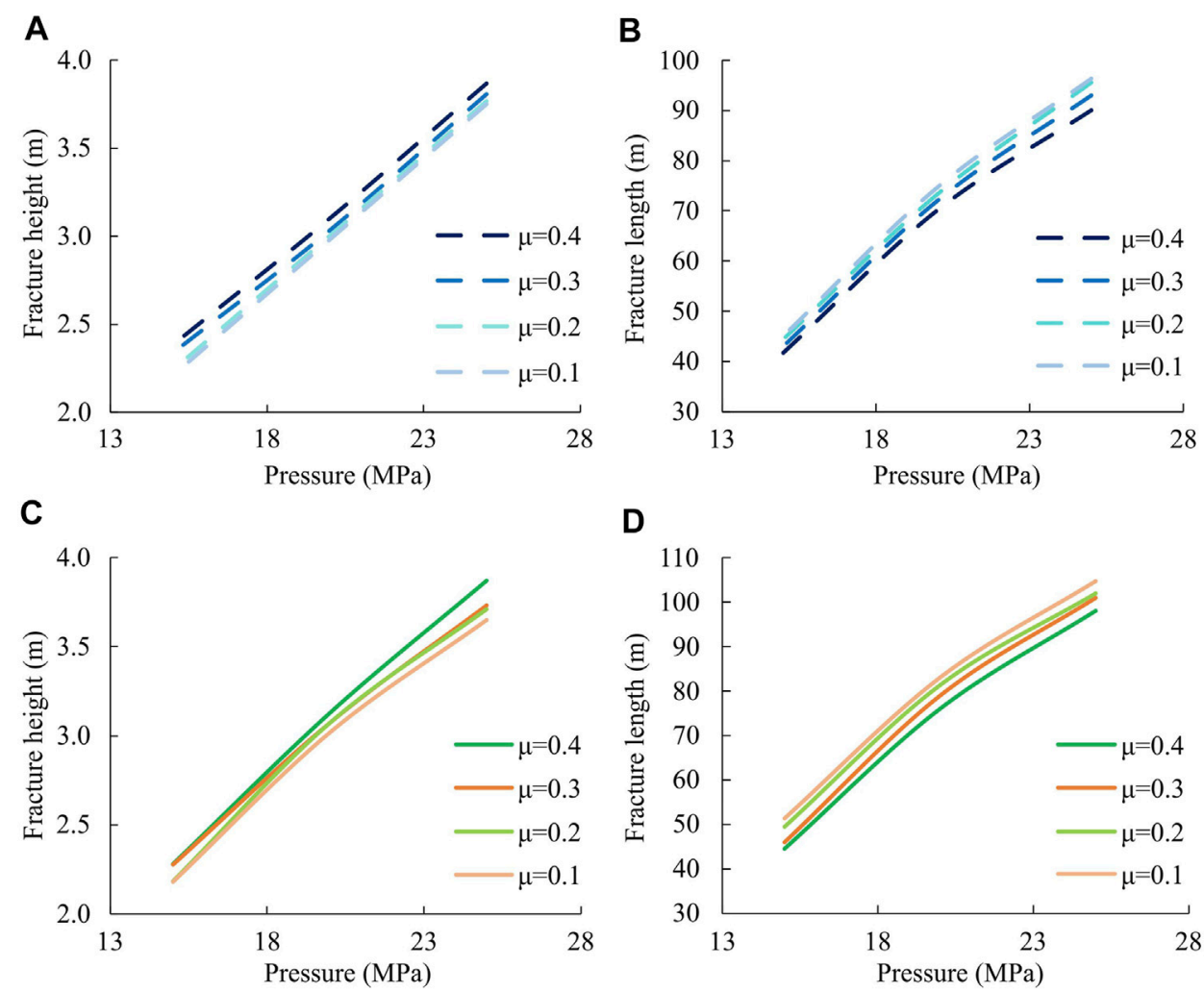

FIGURE 11 | Fracture parameters under different Poisson's ratio of the roof and floor (A) The fracture height of the No. 9 coal seam. (B) The fracture length of the No. 9 coal seam. (C) The fracture height of the No. 13 coal seam. (D) The fracture length of the No. 13 coal seam.

simulation results was verified by the comparison of experimental parameters and field investigation. In addition, the results prove the feasibility of combined seam fracturing of the No. 9 and No. 13 coal seams.

\subsection{Parametric Study on Fracture Propagation}

The coal measure strata in eastern Yunnan are mainly composed of dark-gray fine clastic rock, siltstone, sandy mudstone, and coal. The coal measure gas reservoir characterized by the interaction of multiple thin coal seams is obviously different from the conventional single-layer fracturing process. The influence of different parameters on hydraulic fracture geometry and the feasibility of combined seam fracturing can be studied by numerical simulation. Based on the numerical simulation model established in 4.1 , the effect of multiple parameters including elasticity modulus, Poisson's ratio, and thickness of fracture propagation was studied.

\subsubsection{Young's Modulus of the Coal Seam}

To investigate the effects of Young's modulus of the coal seam on the fracture extension, changing the Young's modulus parameter of No. 13 coal seam and other parameters remain unaltered. The Young's modulus of No. 13 coal seam was set to 2.0, 4.0, 6.0, and
8.0 GPa, respectively. The simulation results are shown in Figure 8. With an increase in the Young's modulus of the No. 13 coal seam, the length and the height of the No. 9 coal seam decreased, while the fracture height of the No. 13 coal seam decreased and the length increased. The results also indicate that the slope of the increase in fracture length decrease as the pressure increases. It shows that in the later stage of fracturing, the ability to generate the fracture length is reduced. The high difference in Young's modulus of the coal seams is not suitable for combined seam fracturing because the difference in the height is significant and leads to the height of one of the coal seams being much less than the thickness of the coal seam.

\subsubsection{Young's Modulus of the Roof and Floor}

The roof of the No. 9 coal seam and the floor of the No. 13 coal seam were sandy mudstone, and Young's modulus was $16.135 \mathrm{GPa}$. Young's modulus is set to $10,12,14,16$, and $18 \mathrm{GPa}$ to investigate the influence of the roof and floor on the fracture's propagation. As shown in Figure 9, regardless of the No. 9 or No. 13 coal seam, the fracture height and the fracture length all decrease with the increase in the Young's modulus of the roof and floor. In other words, the roof and floor have large Young's modulus, which will prevent the increase in fracture height. Also, lower modulus contrast between the coal seam and adjacent layers are more beneficial in forming a longer fracture in coal seams. The result is consistent with Li's simulation (Li et al., 2014). 


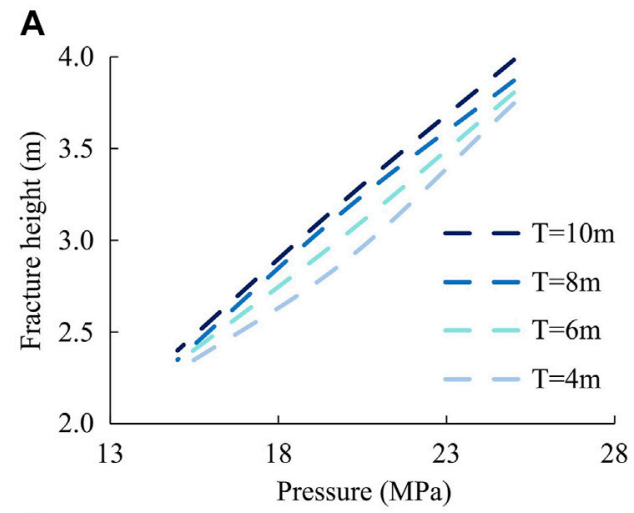

C

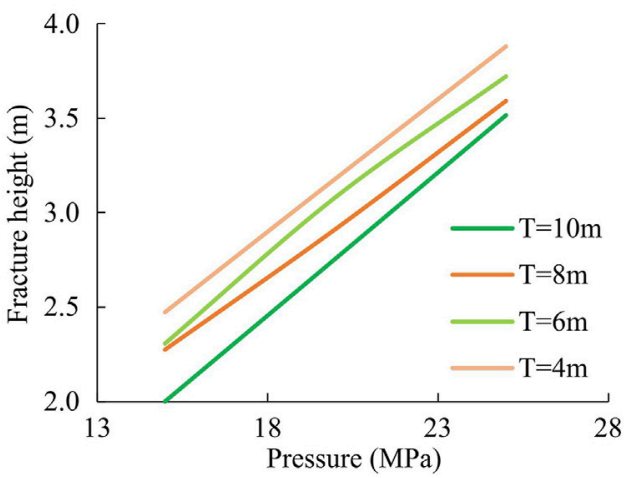

B

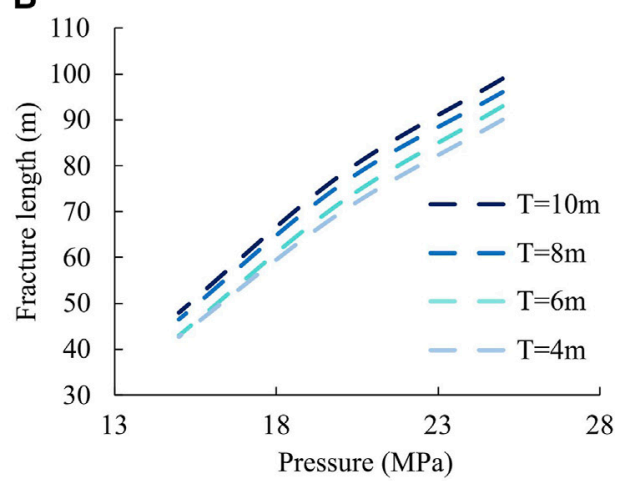

D

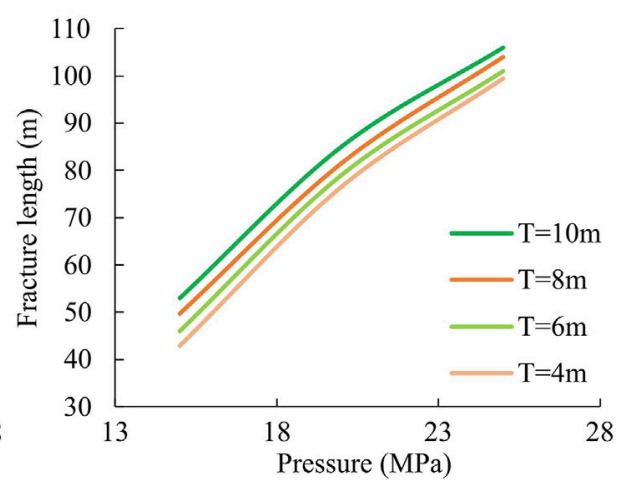

FIGURE 12 |Fracture parameters under different thicknesses of No. 13 coal seam. (A) The fracture height of the No. 9 coal seam. (B) The fracture length of the No. 9 coal seam. (C) The fracture height of No. 13 coal seam. (D) The fracture length of the No. 13 coal seam.

\subsubsection{Poisson's Ratio of the Coal Seam}

Poisson's ratio for rocks lies within a narrow range. Poisson's ratio of the No. 13 coal seam was set as $0.2,0.3,0.4$, and 0.5 in this work. The numerical results are shown in Figure 10. With the increase of Poisson's ratio of the No. 13 coal seam, the height and length of the No. 9 coal seam are all increased, the height and length of the No. 13 coal seam are decreased. The height and length are negatively correlated with Poisson's ratio. In addition, Poisson's ratio of the No. 13 coal seam also affects the height and length of the No. 9 coal seam during combined seam fracturing, and there was a positive correlation. These show that the larger the Poisson's ratio of the coal seam the more unfavorable it is for the fracture to propagate, but on the contrary, it is conducive to fracture's propagation in other coal seams in combined seam fracturing. The results also indicate that the length is more sensitive than the height of the fracture to the change in Poisson's ratio. The height of the fracture varied less than $3 \%$ when the Poisson's ratio increased by 0.1 . Generally, the difference in Poisson's ratio between two coal seams can be neglected in while choosing the fracturing method.

\subsubsection{Poisson's Ratio of the Roof and Floor}

Poisson's ratio of a coal seam is greater than the adjacent layers (Hou et al., 2013). So, in this article, Poisson's ratio of adjacent layers is set as 0.1, 0.2, 0.3, and 0.4. From Figure 11, as Poisson's ratio increased, the length of the coal seams decreased slightly, while the height increased slightly. This can be ignored when compared with the effects of other parameters. As for Poisson's ratio of the roof and floor, it should be noted that the effect of it on fracture extension can be ignored when compared with the effects of other parameters due to the limited range.

\subsubsection{Thickness of the Coal Seam}

The thickness of the coal seam is also one of the factors affecting the geometry of the fracture. In general, the thickness of the coal seam is within $10 \mathrm{~m}$. Hence, the thickness of the No. 13 coal seam was set as 4, 6, 8, and $10 \mathrm{~m}$. Figure 12 demonstrates the relationship between fracture propagation and thickness. On the one hand, an increase in the thickness of the No. 13 coal seam resulted in a decrease in the fracture height and an increase in the fracture length, which further confirmed the conclusions proposed by Li et al. (2014). On the other hand, the change of the thickness of the No. 13 coal seam also affected the fracture propagation of the No. 9 coal seam, and the height and length of the No. 9 coal seam showed increasing trends with an increase in thickness.

Research proved that the main reason for the difference in fracture propagation between the No. 9 and No. 13 coal seams is that the thickness and Young's modulus of the No. 9 coal seam are less than that of the No. 13 coal seam, which is conducive to the extension of the height, while the thickness and the Young's modulus of the No. 13 coal seam are high, which inhibit the extension of the height but facilitate the extension of the length. 

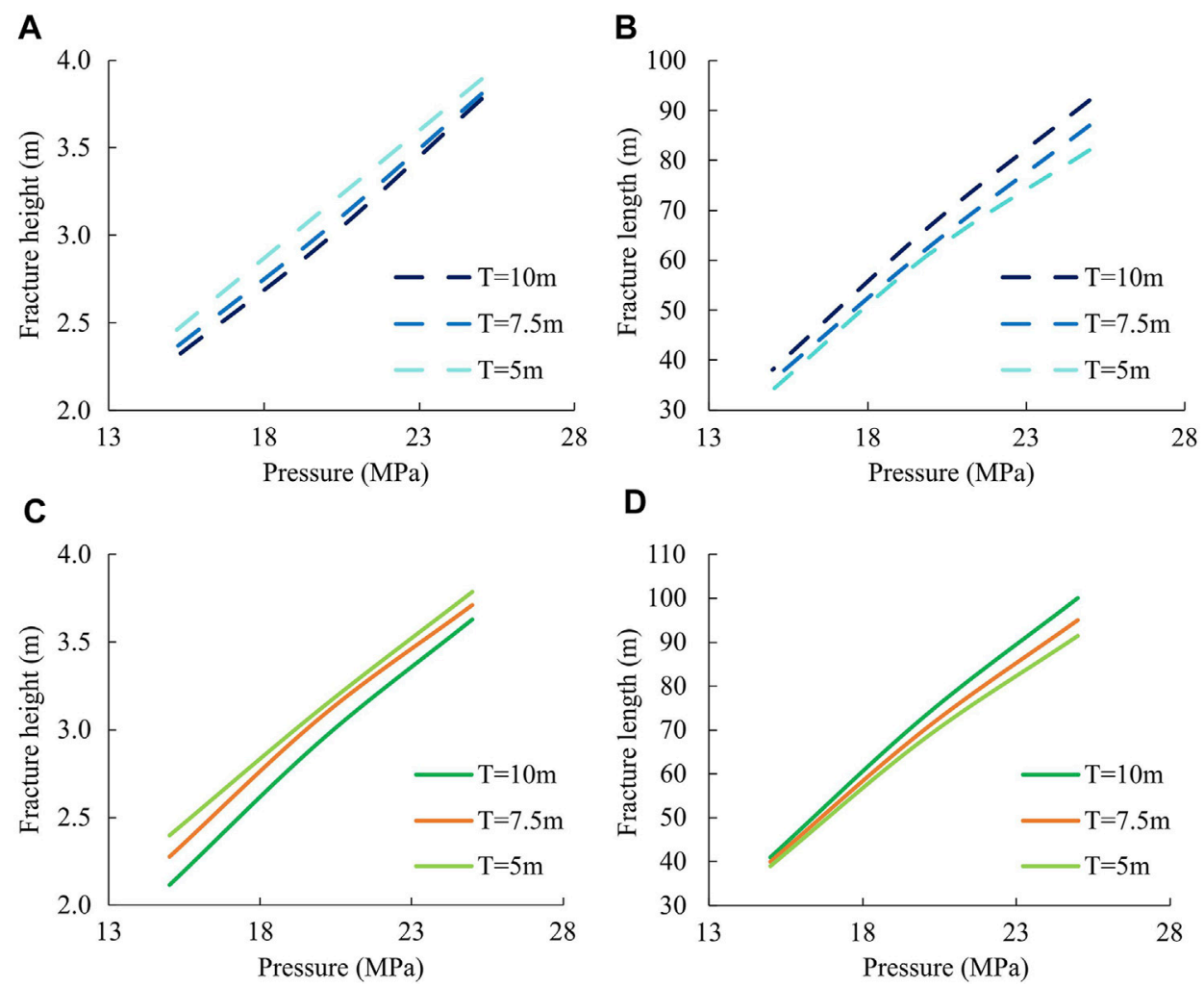

D

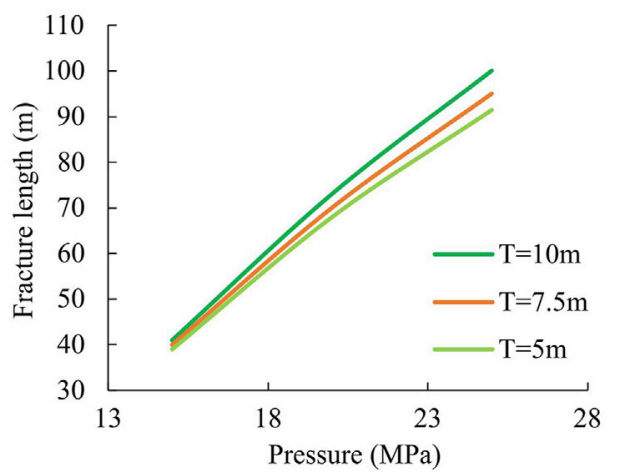

FIGURE 13 |Fracture parameters under different thicknesses of the interlayer (A) The fracture height of the No. 9 coal seam. (B) The fracture length of the No. 9 coal seam. (C) The fracture height of the No. 13 coal seam. (D) The fracture length of the No. 13 coal seam.

\subsubsection{Thickness of the Interlayered Rock}

Jia et al. (2016) proposed that the thickness of the interlayered rock is one of the main factors to control a large fracture network formation. The thickness was set as $5 \mathrm{~m}, 7.5 \mathrm{~m}$, and $10 \mathrm{~m}$ to study the effect of interlayer thickness on fracture propagation, and the result is shown in Figure 13. The height of the fracture decreased when the thickness of the interlayer increased. It demonstrated that the smaller the thickness of the interlayered rock, the greater the probability that the fracture will penetrate the coal seam. In addition, the increase in thickness leads to an increase in the length of the fracture, which is due to the reduction in the interaction between the cracks.

\section{CONCLUSION}

In this study, the two-dimensional hydraulic fracture model of combined seam fracturing in coal seams was established based on the cohesive element model. Then, the geometry of the combined seam fractures was studied by the finite element method. This article also analyzes the influence of different parameters on fracture propagation by means of numerical simulation. The result can be summarized as follows:

(1) The No. 9 and No. 13 coal seams have insignificant difference in the fracture geometries under the same fracturing pressure, and the initiation pressure was $13.31 \mathrm{MPa}$ and $13.89 \mathrm{MPa}$, respectively. The fracture height of the No. 9 coal seam is higher. In contrast, the fracture length of the No. 13 coal seam is longer. The reliability of the simulation results was verified by the comparison of experimental parameters and field investigation. The feasibility of combined seam fracturing in eastern Yunnan was proved by numerical simulation results.

(2) The difference in mechanical properties between coal seams is one of the key factors for combined seam fracturing. Young's modulus has a significant impact on hydraulic fracture propagation. The higher value of Young's modulus is not conducive to the extension of the fracture height, but the length of the fracture increases when the value of the modulus increases. The significant difference in Young's modulus between adjacent layers will inhibit the longitudinal propagation of fractures.

(3) The effect of Poisson's ratio on the hydraulic fracture propagation is mainly reflected in the fracture length and has no significant effect on the fracture height, whether for the coal seam or adjacent layer. In a certain range, the value of Poisson's ratio was positively correlated with the fracture length. However, due to the limited range of Poisson's ratio, the effect of it on fracture extension can be ignored when compared with the effects of other parameters. 
(4) In the process of combined seam fracturing, both coal seam thickness and interlayer thickness affect the hydraulic fracture propagation. In a certain range, the effect of coal seam thickness on fracture length shows a positive correlation. The regularity of the effect of coal seam thickness on fracture height was not significant. Moreover, a thick interlayer inhibited the extension of fracture height and promote the extension of fracture length.

\section{DATA AVAILABILITY STATEMENT}

The raw data supporting the conclusions of this article will be made available by the authors, without undue reservation.

\section{REFERENCES}

Batchelor, G. (1967). An Introduction to Fluid Dynamics: Cambridge. London: Cambridge University Press.

Cao, W., Yildirim, B., Durucan, S., Wolf, K.-H., Cai, W., Agrawal, H., et al. (2021). Fracture Behaviour and Seismic Response of Naturally Fractured Coal Subjected to True Triaxial Stresses and Hydraulic Fracturing. Fuel 288, 119618. doi:10.1016/j.fuel.2020.119618

Chen, Y., Zuo, J., Liu, D., and Wang, Z. (2019). Deformation Failure Characteristics of Coal-Rock Combined Body under Uniaxial Compression: Experimental and Numerical Investigations. Bull. Eng. Geol. Environ. 78 (5), 3449-3464. doi:10. 1007/s10064-018-1336-0

Chen, S., Tang, D., Tao, S., Liu, P., and Mathews, J. P. (2021). Implications of the In Situ Stress Distribution for Coalbed Methane Zonation and Hydraulic Fracturing in Multiple Seams, Western Guizhou, China. J. Pet. Sci. Eng. 204, 108755. doi:10.1016/j.petrol.2021.108755

Chen, Z. (2012). Finite Element Modelling of Viscosity-Dominated Hydraulic Fractures. J. Pet. Sci. Eng. 88-89, 136-144. doi:10.1016/j.petrol.2011.12.021

Eremin, M. (2020). Three-dimensional Finite-Difference Analysis of Deformation and Failure of Weak Porous Sandstones Subjected to Uniaxial Compression. Int. J. Rock Mech. Mining Sci. 133, 104412. doi:10.1016/j.ijrmms.2020.104412

Geertsma, J., and De Klerk, F. (1969). A Rapid Method of Predicting Width and Extent of Hydraulically Induced Fractures. SPE J. Pet. Technol. 21, 1571-1581. doi:10.2118/2458-pa

Gercek, H. (2007). Poisson's Ratio Values for Rocks. Int. J. Rock Mech. Mining Sci. 44, 1-13. doi:10.1016/j.ijrmms.2006.04.011

Guoxi, C., Bo, J., Ming, L., Fengli, L., and Shaochun, X. (2020). Quantitative Characterization of Fracture Structure in Coal Based on Image Processing and Multifractal Theory. Int. J. Coal Geology. 228, 103566. doi:10.1016/j.coal.2020. 103566

Hou, B., Chen, M., Wang, Z., Yuan, J., and Liu, M. (2013). Hydraulic Fracture Initiation Theory for a Horizontal Well in a Coal Seam. Pet. Sci. 10, 219-225. doi:10.1007/s12182-013-0270-9

Hu, Q., Liu, L., Li, Q., Wu, Y., Wang, X., Jiang, Z., et al. (2020). Experimental Investigation on Crack Competitive Extension during Hydraulic Fracturing in Coal Measures Strata. Fuel 265, 117003. doi:10.1016/j.fuel. 2019.117003

Islam, M. R., Hayashi, D., and Kamruzzaman, A. B. M. (2009). Finite Element Modeling of Stress Distributions and Problems for Multi-Slice Longwall Mining in Bangladesh, with Special Reference to the Barapukuria Coal Mine. Int. J. Coal Geology. 78, 91-109. doi:10.1016/j.coal.2008.10.006

Jia, J., Cao, L., Sang, S., Yi, T., and Zhou, X. (2016). A Case Study on the Effective Stimulation Techniques Practiced in the Superposed Gas Reservoirs of CoalBearing Series with Multiple Thin Coal Seams in Guizhou, China. J. Pet. Sci. Eng. 146, 489-504. doi:10.1016/j.petrol.2016.07.005

Jiang, T., Zhang, J., and Wu, H. (2016). Experimental and Numerical Study on Hydraulic Fracture Propagation in Coalbed Methane Reservoir. J. Nat. Gas Sci. Eng. 35, 455-467. doi:10.1016/j.jngse.2016.08.077

\section{AUTHOR CONTRIBUTIONS}

KW: conceptualization, formal analysis, writing review, and editing. ST: resources, funding acquisition, project administration, review, and editing. SZ: resources, supervision, review, and editing. YG: formal analysis, data curation, and writing. DL: formal analysis and visualization. $\mathrm{ZN}$ : investigation and visualization.

\section{FUNDING}

This work was supported by the National Natural Science Foundation of China (Grant Nos. U1910205 and 41872178) and the National Science and Technology Major Project of China (2016ZX05044-001).

Jiang, Z., Li, Q., Hu, Q., Liang, Y., Xu, Y., Liu, L., et al. (2020). Acoustic Emission Characteristics in Hydraulic Fracturing of Stratified Rocks: A Laboratory Study. Powder Tech. 371, 267-276. doi:10.1016/j.powtec. 2020.05.050

Ju, W., Jiang, B., Miao, Q., Wang, J., Qu, Z., and Li, M. (2018). Variation of In Situ Stress Regime in Coal Reservoirs, Eastern Yunnan Region, South China: Implications for Coalbed Methane Production. AAPG Bull. 102 (11), 2283-2303. doi:10.1306/04241817376

Jun Lu, J., Yin, G., Zhang, D., Gao, H., Li, C., and Li, M. (2020). True Triaxial Strength and Failure Characteristics of Cubic Coal and sandstone under Different Loading Paths. Int. J. Rock Mech. Mining Sci. 135, 104439. doi:10. 1016/j.ijrmms.2020.104439

Lan, F., Qin, Y., Wang, A., Li, M., and Wang, G. (2020). The Origin of High and Variable Concentrations of Heavy Hydrocarbon Gases in Coal from the Enhong Syncline of Yunnan, China. J. Nat. Gas Sci. Eng. 76, 103217. doi:10. 1016/j.jngse.2020.103217

Lekontsev, Y. M., and Sazhin, P. V. (2015). Directional Hydraulic Fracturing in Difficult Caving Roof Control and Coal Degassing. J. Min Sci. 50, 914-917. doi:10.1134/S106273911405010X

Li, Q., and Xing, H. (2015). Numerical Analysis of the Material Parameter Effects on the Initiation of Hydraulic Fracture in a Near Wellbore Region. J. Nat. Gas Sci. Eng. 27, 1597-1608. doi:10.1016/j.jngse.2015.10.023

Li, D. Q., Zhang, S. C., and Zhang, S. A. (2014). Experimental and Numerical Simulation Study on Fracturing through Interlayer to Coal Seam. J. Nat. Gas Sci. Eng. 21, 386-396. doi:10.1016/j.jngse.2014.08.022

Li, S., Tang, D., Pan, Z., Xu, H., and Guo, L. (2015). Evaluation of Coalbed Methane Potential of Different Reservoirs in Western Guizhou and Eastern Yunnan, China. Fuel 139, 257-267. doi:10.1016/j.fuel.2014.08.054

Li, Y., Yang, J., Pan, Z., and Tong, W. (2020). Nanoscale Pore Structure and Mechanical Property Analysis of Coal: An Insight Combining AFM and SEM Images. Fuel 260, 116352. doi:10.1016/j.fuel.2019.116352

Li, N., Sun, W., Huang, B., Chen, D., Zhang, S., and Yan, M. (2021). Acoustic Emission Source Location Monitoring of Laboratory-Scale Hydraulic Fracturing of Coal under True Triaxial Stress. Nat. Resour. Res. 30 (3), 2297-2315. doi:10.1007/s11053-021-09821-9

Liang, Y., Cheng, Y., Zou, Q., Wang, W., Ma, Y., and Li, Q. (2017). Response Characteristics of Coal Subjected to Hydraulic Fracturing: An Evaluation Based on Real-Time Monitoring of Borehole Strain and Acoustic Emission. J. Nat. Gas Sci. Eng. 38, 402-411. doi:10.1016/j.jngse.2017.01.001

Liu, C., Huang, X., Yue, W., and Zhang, C. (2020). Extension of Grouting-Induced Splitting Fractures in Materials Similar to Coal Rocks Containing Prefabricated Fractures. J. Geophys. Eng. 17, 670-685. doi:10.1093/jge/gxaa021

McDaniel, B. W. (1990). Hydraulic Fracturing Techniques Used for Stimulation of Coalbed Methane Wells. SPE East. Reg. Meet. 21292. doi:10.2118/21292-MS

Meng, Z., Zhang, J., and Wang, R. (2011). In-situ Stress, Pore Pressure and Stressdependent Permeability in the Southern Qinshui Basin. Int. J. Rock Mech. Mining Sci. 48, 122-131. doi:10.1016/j.ijrmms.2010.10.003 
Nasedkina, A. A., and Trufanov, V. N. (2006). Numerical Modeling of Hydrofracturing in a Multilayer Coal Seam. J. Min Sci. 42, 54-62. doi:10. 1007/s10913-006-0029-4

Ni, X., Su, X., and Li, Y. (2010). Study of the Key Technologies of the Hydraulic Fracturing Used in Multi-Layer Coal Seam. J. China Univ. Mining Tech. 39, $728-732+739$.

Özgen Karacan, C. (2009). Elastic and Shear Moduli of Coal Measure Rocks Derived from Basic Well Logs Using Fractal Statistics and Radial Basis Functions. Int. J. Rock Mech. Mining Sci. 46, 1281-1295. doi:10.1016/j. ijrmms.2009.04.002

Pan, J., Meng, Z., Hou, Q., Ju, Y., and Cao, Y. (2013). Coal Strength and Young's Modulus Related to Coal Rank, Compressional Velocity and Maceral Composition. J. Struct. Geology. 54, 129-135. doi:10.1016/j.jsg.2013.07.008

Qin, L., Zhai, C., Liu, S., and Xu, J. (2018). Mechanical Behavior and Fracture Spatial Propagation of Coal Injected with Liquid Nitrogen under Triaxial Stress Applied for Coalbed Methane Recovery. Eng. Geology. 233, 1-10. doi:10.1016/j. enggeo.2017.11.019

Ren, Q., Jiang, Y., Wang, P., Wu, G., and Noraei Danesh, N. (2021). Experimental and Numerical Simulation Study of Hydraulic Fracture Propagation during Coalbed Methane Development. Geofluids 2021, 1-12. doi:10.1155/2021/ 3632997

Shet, C., and Chandra, N. (2002). Analysis of Energy Balance when Using Cohesive Zone Models to Simulate Fracture Processes. J. Eng. Mater. Tech. 124 (4), 440-450. doi:10.1115/1.1494093

Tang, S., Tang, D., Xu, H., Tao, S., Li, S., and Geng, Y. (2016). Geological Mechanisms of the Accumulation of Coalbed Methane Induced by Hydrothermal Fluids in the Western Guizhou and Eastern Yunnan Regions. J. Nat. Gas Sci. Eng. 33, 644-656. doi:10.1016/j.jngse.2016.05.061

Tomar, V., Zhai, J., and Zhou, M. (2004). Bounds for Element Size in a Variable Stiffness Cohesive Finite Element Model. Int. J. Numer. Meth. Engng. 61, 1894-1920. doi:10.1002/nme.1138

Wang, Z., and Qin, Y. (2019). Physical Experiments of CBM Coproduction: A Case Study in Laochang District, Yunnan Province, China. Fuel 239, 964-981. doi:10. 1016/j.fuel.2018.11.082

Warpinski, N. R., and Teufel, L. W. (1987). Influence of Geologic Discontinuities on Hydraulic Fracture Propagation (Includes Associated Papers 17011 and 17074 ). J. Pet. Tech. 39, 209-220. doi:10.2118/13224-PA

Wessling, S., Kessels, W., Schmidt, M., and Krause, U. (2008). Investigating Dynamic Underground Coal Fires by Means of Numerical Simulation. Geophys. J. Int. 172 (1), 439-454. doi:10.1111/j.1365-246X.2007.03568.x

Xie, B., Yan, Z., Du, Y., Zhao, Z., and Zhang, X. (2019). Determination of Holmquist-Johnson-Cook Constitutive Parameters of Coal: Laboratory Study and Numerical Simulation. Processes 7 (6), 386. doi:10.3390/ pr7060386

Yang, W., Lin, B., Gao, Y., Lv, Y., Wang, Y., Mao, X., et al. (2016). Optimal Coal Discharge of Hydraulic Cutting inside Coal Seams for Stimulating Gas Production: A Case Study in Pingmei coalfield. J. Nat. Gas Sci. Eng. 28, 379-388. doi:10.1016/j.jngse.2015.12.004

Yang, Z., Zhang, Z., Qin, Y., Wu, C., Yi, T., Li, Y., et al. (2018). Optimization Methods of Production Layer Combination for Coalbed Methane Development in Multi-Coal Seams. Pet. Exploration Dev. 45 (2), 312-320. doi:10.1016/S18763804(18)30034-X

Yang, Z., Li, Y., Qin, Y., Sun, H., Zhang, P., Zhang, Z., et al. (2019). Development Unit Division and Favorable Area Evaluation for Joint Mining Coalbed
Methane. Pet. Exploration Dev. 46 (3), 583-593. doi:10.1016/S1876-3804(19) 60038-8

Yinlong Lu, Y., He, M., Wu, B., and Meng, X. (2020). Experimental and Theoretical Analysis of Hydraulic Fracturing and Gas Fracturing of Rock under True Triaxial Compressions. Eng. Fracture Mech. 234, 107100. doi:10.1016/j. engfracmech.2020.107100

Zhang, J. (2014). Numerical Simulation of Hydraulic Fracturing Coalbed Methane Reservoir. Fuel 136, 57-61. doi:10.1016/j.fuel.2014.07.013

Zhang, J., and Bian, X. (2015). Numerical Simulation of Hydraulic Fracturing Coalbed Methane Reservoir with Independent Fracture Grid. Fuel 143, 543-546. doi:10.1016/j.fuel.2014.11.070

Zhang, J., and Roegiers, J.-C. (2010). Discussion on "Integrating Borehole-Breakout Dimensions, Strength Criteria, and Leak-Off Test Results, to Constrain the State of Stress across the Chelungpu Fault, Taiwan". Tectonophysics 492, 295-298. doi:10.1016/j.tecto.2010.04.038

Zhang, X., Li, P., Yang, Y., and Du, Z. (2017). Characteristics of P-Wave and S-Wave Times and Their Relationship with Young's Modulus of Coals with Different Degrees of Deformation. Arab J. Geosci. 10 (4), 75. doi:10.1007/s12517-017-2855-x

Zhang, J., Ai, C., Li, Y.-w., Che, M.-g., Gao, R., and Zeng, J. (2018). Energy-Based Brittleness Index and Acoustic Emission Characteristics of Anisotropic Coal under Triaxial Stress Condition. Rock Mech. Rock Eng. 51 (11), 3343-3360. doi:10.1007/s00603-018-1535-9

Zhang, S., Wu, C., and Liu, H. (2020). Comprehensive Characteristics of Pore Structure and Factors Influencing Micropore Development in the Laochang Mining Area, Eastern Yunnan, China. J. Pet. Sci. Eng. 190, 107090. doi:10.1016/ j.petrol.2020.107090

Zhang, Z., Qin, Y., Wang, G., Sun, H., You, Z., Jin, J., et al. (2021). Evaluation of Coal Body Structures and Their Distributions by Geophysical Logging Methods: Case Study in the Laochang Block, Eastern Yunnan, China. Nat. Resour. Res. 30 (3), 2225-2239. doi:10.1007/s11053-021-09834-4

Zhao, H., Wang, X., Liu, Z., Yan, Y., and Yang, H. (2018). Investigation on the Hydraulic Fracture Propagation of Multilayers-Commingled Fracturing in Coal Measures. J. Pet. Sci. Eng. 167, 774-784. doi:10.1016/j.petrol.2018.04.028

Zhao, X., Huang, B., and Grasselli, G. (2021). Numerical Investigation of the Fracturing Effect Induced by Disturbing Stress of Hydrofracturing. Front. Earth Sci. 9, 751626. doi:10.3389/feart.2021.751626

Conflict of Interest: The authors declare that the research was conducted in the absence of any commercial or financial relationships that could be construed as a potential conflict of interest.

Publisher's Note: All claims expressed in this article are solely those of the authors and do not necessarily represent those of their affiliated organizations, or those of the publisher, the editors, and the reviewers. Any product that may be evaluated in this article, or claim that may be made by its manufacturer, is not guaranteed or endorsed by the publisher.

Copyright () 2022 Wang, Tang, Zhang, Guo, Lin and Niu. This is an open-access article distributed under the terms of the Creative Commons Attribution License (CC $B Y)$. The use, distribution or reproduction in other forums is permitted, provided the original author(s) and the copyright owner(s) are credited and that the original publication in this journal is cited, in accordance with accepted academic practice. No use, distribution or reproduction is permitted which does not comply with these terms. 